\title{
Erratum to: Langhinrichsen-Rolling's Confirmation of the Feminist Analysis of Intimate Partner Violence: Comment on "Controversies Involving Gender and Intimate Partner Violence in the United States"
}

\author{
Michael P. Johnson
}

Published online: 12 March 2010

(C) Springer Science+Business Media, LLC 2010

\section{Erratum to: Sex Roles}

\section{DOI 10.1007/s11199-009-9697-2}

In "Langhinrichsen-Rolling's Confirmation of the Feminist Analysis of Intimate Partner Violence: Comment on 'Controversies Involving Gender and Intimate Partner Violence in the United States"” (Volume 62, Numbers 3/4, February 2010, DOI: $10.1007 / \mathrm{s} 11199-009-9697-2)$ LanghinrichsenRohling's name was erroneously misspelled in the title, the abstract, and the conclusion. The correct spelling is Langhinrichsen-Rohling.

The online version of the original article can be found at http://dx.doi. org/10.1007/s11199-009-9697-2.

M. P. Johnson $(\bowtie)$

Sociology, Women's Studies, and African and African American

Studies, Penn State,

University Park, PA, USA

e-mail: mpj@psu.edu

URL: www.personal.psu.edu/mpj 